\title{
Política energética e construção de hidrelétricas na primeira metade do Século XX: reflexões sobre o caso
} paranaense

\author{
Energy policy and hydro building in the first half of the \\ twentieth century: reflections on the case of the Paraná-State- \\ Brazil
}

Cezar Karpinski $i^{*}$

RESUMO

Neste artigo analiso algumas ações governamentais que legitimaram a constituição de uma política hidroenergética no Estado do Paraná entre as décadas de 1940 e 1950. Dedico especial atenção ao início das projeções e construções de hidrelétricas no rio Iguaçu, especialmente a história da instalação da Hidrelétrica Caiacanga, primeira a ser instalada no curso deste rio. Utilizando o discurso como categoria analítica, procuro refletir sobre a emergência do modelo hidroenergético e sua defesa e legitimação na história contemporânea do Brasil. A análise da construção da Usina do Caiacanga deslinda um processo histórico que nos remete a projetos elaborados no início do Século XX, suas formas tecnológicas e o papel que ocupam os rios e suas quedas d'água nos planos governamentais. As fontes utilizadas foram Mensagens de Governo, o Plano Hidro-energético Paranaense de 1949 e um Relatório Técnico publicado em 1951 no Paraná.

Palavras chave: Energia. Rio Iguaçu. Caiacanga. Hidrelétricas. Meio ambiente.

ABSTRACT

In this article analyzes some government actions that contributed to the creation of a hydropower policy in the Paraná state, Brazil, between the 1940s and 1950s. I dedicate a special attention to the beginning of the projections and hydroelectric constructions in the Iguaçu River, especially the history of the installation of Caiacanga Hydroelectric, first to be installed in the course of this river. Using speech as an analytical category, I try to reflect on the emergence of the hydroenergetic model and its defense and legitimation in the contemporary history of Brazil. The analysis of the construction of the Caiacanga Hydroelectric to reveal a historical process that leads us to projects elaborate in the early twentieth century,

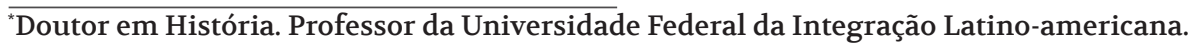


its technological forms and the role that occupy the rivers and its waterfalls in government plans. The sources used were government messages, the Hydro-Energy Plan of the Parana State dated 1949 and a Technical Report published in 1951 in the Paraná State, Brazil.

Keyword: Electricity. Iguaçu River. Caiacanga Plant. Hydroelectric. Environmental.

\section{Considerações iniciais}

A bibliografia acadêmica sobre a implantação de hidrelétricas no Brasil, de modo geral, tem se debruçado sobre os impactos sociais, ambientais, culturais e, principalmente, os conflitos sociais originados destes e nestes processos. Nessa seara, os historiadores têm travado um rico diálogo interdisciplinar possibilitando um acúmulo significativo de relatos empíricos e de distintas metodologias. Sob esta perspectiva, obras como a de Verdum (2007), Naval e Parente (2009), Rocha (2014) e Maia et al. (2013) são bastante significativas. Nestes trabalhos e em outros que poderiam ser citados aqui, encontramos estudos que partilham aspectos "comuns" no caso das implantações de Hidrelétricas. Apenas como exemplo, podemos citar os processos de deslocamento compulsório, desterritorialização, estratégias governamentais e de empresas contratadas para a instalação rápida dos seus projetos, inúmeros estudos ambientais "cegos" aos graves problemas socioambientais advindos da construção da barragem, os processos de resistência dos movimentos sociais e o desrespeito à cultura material e imaterial das populações tradicionais.

Entretanto, parece que essa produção advinda de mais de três décadas de pesquisas junto às populações atingidas, a qual se inclui a minha, não têm apontado mudanças significativas na política hidroenergética do nosso país. Isto porque a cada novo processo de instalação de hidrelétricas, os mesmos problemas são denunciados e novos artigos/teses/dissertações são escritos a partir de velhos problemas sociais e ambientais advindos destes empreendimentos.

Em sua grande maioria, os trabalhos historiográficos têm se detido temporalmente entre as décadas de 1970 e 2000. Destes pesquisadores, uma parcela significativa tem dado ênfase aos resultados de pesquisas que analisaram processos relacionados ao centro-sul do país. Neste grupo de pesquisadores e considerando apenas alguns trabalhos atuais, se encontram as obras de Santos e Reis (2002), Silva e Silva (2011) e Derrosso e Ichikawa (2014). Já nestes primeiros anos do Século XXI, as abordagens sobre a temática das hidrelétricas têm se detido especialmente nos casos relacionados ao Norte e, principalmente, à região amazônica. Aqui, considero importantes trabalhos os artigos de Laverdi (2011), Pinto (2012), Fleury e Almeida (2013) e Sieben e Cleps Jr. (2012).

Contudo, estas pesquisas não chegam a refletir com densidade os processos históricos que antecederam a década de 1970 e que, em grande medida, forneceram as condições de possibilidade para esta política energética pautada na hidroeletricidade, cujos impactos vimos historiando há quase quarenta anos. Em meu entendimento, há uma lacuna historiográfica 
sobre os estudos, projeções, interesses político-econômicos e relações internacionais na constituição de um tipo de política (hidro)energética a ser adotada, tanto no Brasil quanto em outros países da América Latina.

Nesse sentido, tenho já há algum tempo me proposto a historiar sobre o que, efetivamente, poderia ter proporcionado este tipo de política energética no Brasil. Entendo que, como historiador que desde 2001 vem pesquisando a temática "hidrelétricas", preciso direcionar meu olhar para além das invisibilidades e exclusões sociais que temos denunciado nestes anos todos de pesquisa e lutas junto aos atingidos por barragens. Tenho me proposto, com certa relutância e fragilidade argumentativa, a tornar visível a história daquilo que possibilitou estas invisibilidades e exclusões, ou seja, do processo político que legitimou o modelo energético brasileiro. Para isto, é preciso retroceder temporalmente, ir ao encontro de fontes distintas para as quais temos que construir metodologias e nos lançarmos em um complexo universo de práticas discursivas. É o discurso, como categoria analítica, que tem me possibilitado compreender os começos, os meandros e a emergência de ações práticas que incidiram sobre os projetos e construções de hidrelétricas. Por meio destes estudos, abre-se um caminho quase inexplorado pela historiografia contemporânea que nos remete a projetos hidroelétricos elaborados no início do século passado, suas formas tecnológicas, as relações conflituosas entre Estado e empresas privadas na definição da posse dos bens naturais, neste caso específico, os rios ou as quedas d'água. Além disso, é possível visualizar distintas formas de percepção e relação com o ambiente circundante aos rios, bem como a difícil e lenta concepção de que este espaço é historicamente constituído por comunidades humanas e não humanas.

Sobre a política energética propriamente dita, é possível afirmar que na "era Vargas" o Estado passou a considerar a energia como uma prioridade política do governo nacional. Entendo que a promulgação do Código das Águas em 1934 foi o início de uma profunda transformação do setor hidroenergético brasileiro que, até então, estava sob o domínio, quase que exclusivamente, de companhias estrangeiras. Desta forma, o Estado inicia um processo de centralização institucional do setor de energia, sendo o Código das Águas um coroamento desta intenção de estatizar o setor. De acordo com o Centro de Memória da Eletricidade do Brasil (1988), a postura do Governo Provisório de Vargas, onde o Estado passaria a controlar setores econômicos, se refletiu numa legislação nacionalista que passou a regular a relação de exploração dos recursos naturais. O Código das Águas, especificamente, estabeleceu um postulado básico e inovador no regime jurídico do Brasil ao distinguir propriedade de solo e propriedade de quedas d'águas e outras fontes de energia hidráulica. Sendo assim, "ao caracterizar as quedas d'água como bens imóveis, distintos e não integrantes das terras em que se encontram, o Código consagrou o regime das autorizações e concessões para os aproveitamentos hidrelétricos" (CENTRO DA MEMÓRIA DA ELETRICIDADE NO BRASIL, 1988, p.82).

A partir de então, entidades foram criadas, concessões foram feitas e inúmeras hidrelétricas foram projetadas e construídas, trazendo com elas formas estatizadas de apropriação e uso da 
água. Os rios passaram a ser estudados, mapeados e avaliados para que, o maior número deles, pudesse obedecer a essa lógica de aproveitamento energético. Os governantes brasileiros passaram a vislumbrar as hidrelétricas como a única saída para a crise de energia pela qual passava em meados do Século XX e para aquelas que ainda viriam nas décadas futuras. Através de estudos avançados de estimativas e potencial energético do país, o Brasil passou a constituir um discurso que positivava a instalação de hidrelétricas e que estas trariam a energia capaz de acelerar o crescimento e o progresso econômico.

Entretanto, entre o início das medidas de centralização dos serviços de geração e transmissão de eletricidade, cujo Código das Águas é um marco, e o monopólio estatal, propriamente dito, um longo processo político e econômico se instaurou no setor. As empresas estrangeiras não perderam suas concessões, sofreram apenas sanções e medidas por parte do governo que afetaram diretamente os lucros e os incentivos à expansão do parque gerador de energia, o que aumentou ainda mais a da crise energética. Apesar disso, o andamento da nacionalização e centralização administrativa do setor de energia elétrica do país continuava a se aprofundar, ainda que, pela necessidade de garantir o suprimento de energia em mãos de concessionárias estrangeiras, várias flexibilizações fossem negociadas na aplicação do Código, conforme afirmam Siqueira et al. (1994).

Nesse sentido, tendo como recorte espacial o Estado do Paraná e especificamente os projetos de construção de hidrelétricas no Rio Iguaçu entre os anos de 1900-1969, apresento, neste artigo, algumas contribuições para a historiografia sobre as hidrelétricas. O objetivo aqui é propor uma análise sobre como o Estado, por meio de governos específicos, construiu um discurso pontual e incisivo que corroborou a constituição de um tipo específico de política hidroenergética. Selecionei de forma precisa o impacto do Plano Nacional de Eletrificação no Estado do Paraná, por meio de um dos seus principais defensores, o governador Moysés Lupion. O enfoque será o discurso sobre o grande potencial de força hidráulica dos rios paranaenses e do Iguaçu, em particular, com o objetivo de historiar o início dos estudos que nas décadas vindouras desencadeariam as profundas transformações sociais e ambientais nas regiões dos grandes saltos deste rio. ${ }^{1}$

Para esta etapa da análise, as principais fontes foram as Mensagens de Governo à Assembleia Legislativa, os Relatórios apresentados pelas secretarias de Estado e o "Plano Hidro-Elétrico Paranaense Moysés Lupion". Este último, embora almeje ser um estudo genuinamente paranaense, principalmente pela identidade atrelada ao nome do governador, obedece, em grande medida, o Plano Nacional de Eletrificação, nos moldes da política do governo de Getúlio Vargas. Por estes documentos, percebemos a constituição de estratégias governamentais para a incorporação dos projetos constantes no Plano por meio de um discurso ufanista sobre a

${ }^{1} \mathrm{O}$ rio Iguaçu tem suas nascentes nas proximidades de Curitiba-Pr e, de leste a oeste, percorre o território do sul do Estado, desaguando no rio Paraná, na cidade de Foz do Iguaçu. Neste percurso, ao longo do século XX e especialmente depois da década de 1970, foram construídas cinco usinas hidrelétricas, todas de grande porte e com uma produção significativa de energia. Neste século, está em construção a última usina projetada entre as cidades de Capitão Leônidas Marques e Capanema-Pr, nas proximidades do Parque Nacional do Iguaçu, considerado Patrimônio Natural da Humanidade pela UNESCO. 
riqueza hidroenergética dos rios paranaenses. Além disto, o governo inaugura, a partir dos discursos sobre a força elétrica, uma nova forma de fazer política energética no Estado, principalmente com o ideal de modernidade e de tecnologia exposto pelos novos projetos governamentais.

Outro documento essencial para a escrita deste artigo é um dos primeiros relatórios técnicos sobre o andamento das construções de hidrelétricas no Paraná. Este relatório, advindo de um estudo que contou com a colaboração de técnicos estadunidenses, nos possibilita visualizar as idiossincrasias do plano hidroelétrico de Lupion e sua execução. Mostra também a ineficiência técnica de recursos humanos no Brasil e o início de uma história de desperdício de recursos financeiros aplicados em projetos mal elaborados. No entanto, a principal contribuição desta fonte para este artigo foi a presença de dados sobre o primeiro empreendimento hidroelétrico projetado e construído no rio Iguaçu, a hidrelétrica do Salto do Caiacanga.

As discussões e ações governamentais para a construção desta hidrelétrica se iniciaram em 1907 e tinham como objetivo gerar energia para o abastecimento de Curitiba. Contudo, uma série de fatores impediu sua construção e foram relatados em documentos oficiais até 1914. Deste ano em diante, havia um vazio documental sobre esta que seria a primeira central hidrelétrica do Estado. Por isso, o estudo elaborado na década de 1950 traz vestígios sobre a história da hidrelétrica de Caiacanga que possibilitam o preenchimento de uma lacuna histórica deste processo que também procuro aprofundar.

\section{Moysés Lupion e o "seu” Plano Hidro-energético para o Paraná}

Na mensagem enviada pelo governador Moysés Lupion à Assembleia Legislativa em 1948, tem-se um pequeno balanço da situação energética do Paraná desde os anos 1920 até o início de seu mandato em 12 de março de 1947. Neste discurso, o governador constrói uma história energética paranaense descentralizada, sem nenhum encaminhamento que visasse uma política organizada do setor e, deste modo, responsável pelo atraso em que se encontrava o Paraná mesmo sendo o "primeiro Estado do Brasil em força hidráulica" (PARANÁ, 1948a, p.8). ${ }^{2}$

Segundo Lupion, todas as ações anteriores ao seu governo tinham advindo de iniciativas dispersas dos municípios que, sem recursos, foram aceitando essas soluções "quase sempre precaríssimas de emergência, com o aproveitamento de elementos insuficientes e as mais das vezes inadequados" mal satisfazendo "às exigências mínimas que deveriam cobrir" (PARANÁ, 1948a, p.8). Esta construção discursiva de Lupion visava incorporar às responsabilidades do Estado do Paraná uma ação que englobasse, engendrasse e reunisse, nas mãos do governo, a questão da energia. Em seu governo, o Paraná inseriu definitivamente a questão energética na agenda política estadual, por meio de um plano geral de eletrificação do Estado, pois, segundo Lupion, não era mais o caso do Paraná se contentar "com pequenos remendos à situação atual, com novas pequenas soluções provisórias, que não seria isso mais do que adiar de mais um dia a solução efetiva do problema" (PARANÁ, 1948a, p.8). 
Pensar a energia para o Estado do Paraná na década de 1940 requeria, nas palavras de Lupion, um adensamento de forças, criando setores dentro da máquina administrativa que estudassem e viabilizassem os recursos hídricos do Estado para a geração de eletricidade. $O$ enunciado que se destaca neste discurso é o da unificação do Estado num plano "geral" que norteasse uma "nova" política energética. Era necessário, segundo Lupion, não apenas resolver os problemas presentes com soluções paliativas, mas iniciar um processo que pensasse a energia para o Estado em longo prazo, fazendo com que o Paraná se tornasse na questão de energia assim como São Paulo, Minas Gerais e Rio de Janeiro, grandes consumidores e geradores de eletricidade no Brasil dos anos 1940. O desenvolvimento futuro do Paraná dependia desse aumento na geração de energia:

Compreendendo isso, foi que fizemos elaborar um plano geral, relativamente ao problema da energia elétrica em nosso Estado, baseado no estudo dos numerosos casos isolados que passam a ser, dêsse modo, apreciados de uma só vez, e com soluções adequadas não só às necessidades presentes, mas ao nosso desenvolvimento futuro (PARANÁ, 1948a, p.8 grifo meu).

Entra em cena o discurso que apelava para os números, pois as medidas em kWs passam a constituir uma rede de necessidades que, por sua vez, focaliza a construção de hidrelétricas como o único caminho possível para a saída da crise. Lupion tornava público aos legisladores a superioridade de São Paulo, do sul do Rio de Janeiro e da Capital Federal da época cujo consumo em $\mathrm{kW} / \mathrm{h}$ por habitante era quase o dobro do Paraná, o que, certamente, constituía a urgência na aprovação de leis que agilizassem um processo de reversão desta "inferioridade" paranaense. Os discursos governamentais que até então apenas questionavam qualidades de serviço e negociavam concessões, ganharam as "realidades" numéricas diagnosticadas por estudos metódicos e comparativos, fazendo projeções e estimando custo/benefícios e lucros para o mercado energético futuro. Às comparações internas juntam-se os números dos países considerados desenvolvidos onde, segundo Lupion, o consumo de $\mathrm{kW} / \mathrm{h}$ era dez vezes maior que o do Paraná dos anos 1940. Dessa forma, incorporam-se novos argumentos aos "velhos" anseios de estatizar o setor de energia no Estado, obedecendo, obviamente, uma lógica nacional inaugurada em 1934 com o Código das Águas, mas que, até então, pouco se efetivava devido às constantes crises internas e externas advindas também do período da Segunda Guerra Mundial. A partir de então, os números passam a legitimar o discurso governamental no anseio de agregar força à questão energética, pois, dadas as circunstâncias de tais números

[...] bem podemos avaliar a penúria de nossa situação atual. Desejando-se elevar o Paraná pelo menos ao nível da zona central do Brasil, teremos, porém, de duplicar de imediato a potência disponível para triplicá-la dentro do período 
próximo de dez anos. Precisamos elevar os nossos $35.000 \mathrm{Kw}$. à altura dos $130.000 \mathrm{Kw} .$, nos próximos dez anos (PARANÁ, 1948a, p.9).

Para a elevação destes números, o governo de Moisés Lupion já vislumbrava a saída, pois, paralelamente aos estudos comparativos de consumo/geração de $\mathrm{kW} / \mathrm{h}$, se fez o levantamento de quantas quedas d'água o Estado poderia aproveitar para empreendimentos hidrelétricos. Neste breve mapeamento de locais passíveis para hidrelétricas chegou-se ao número de 350 quedas que poderiam ser aproveitadas desde que existisse um plano centralizador, regulador e que viabilizasse a interligação e coordenação das operações de "geração e transmissão de energia elétrica para o suprimento em grosso às mesmas empresas que as redistribuiriam diretamente aos consumidores"(Paraná, 1948a, p.9)

Desta forma, Lupion buscava legitimar, perante a Assembleia, a constituição, em seu governo, do Serviço de Energia Elétrica criado com o Decreto-Lei 664, de 7 de Agosto de 1947 e atrelado à Secretaria de Viação e Obras Públicas (SIQUEIRA et al, 1994, p.92). Segundo Lupion, este grupo estava empenhado em constituir um “órgão auxiliar do Conselho Nacional de Água e Energia Elétrica, a fim de orientar as atividades do Estado em mais estreita colaboração com os órgãos federais superiores" (PARANÁ, 1948a, p.44). Lupion sempre fez questão de afirmar em seus discursos a obediência de seu governo às instituições federais, o que demonstra a construção em âmbito nacional de um engendramento político-econômico que fosse capaz de superar a crise nacional de energia. Desta forma, ainda explicando à Assembleia as ações de seu governo voltadas à energia elétrica, Lupion afirma que:

Obedecendo às recomendações da Comissão Técnica do planejamento de Energia Elétrica, em seu $2^{\circ}$.Congresso Brasileiro de Energia e Indústria, sendo as quais: "No campo administrativo, a intervenção do Govêrno dever-se-á processar na ausência da iniciativa particular, que deverá ser fomentada no sentido de promover o estabelecimento, nas diversas regiões do País, das redes de coordenação...”, o Estado do Paraná dividiu o seu território em três sistemas elétricos, o do sul, $n^{\circ} 1$, o do norte, $n^{\circ} 2$ e o do oeste, $n^{\circ} 3$ (PARANÁ, 1948a, p.44).

Este discurso mostra tanto o caráter interventor estatal na política energética brasileira da década de 1940, quanto as práticas voltadas à centralização de geração e transmissão de energia. Afinal, a divisão do Estado em três zonas elétricas nada mais foi do que o mapeamento da potência instalada e do mercado consumidor de energia. Todos os planos e ações definidos no governo de Moysés Lupion, bem como nos governos seguintes, se pautaram neste mapeamento regional estabelecido "a fim de acentuar a tendência de uma centralização reguladora para a coordenação das operações de geração e transmissão de energia elétrica" (PARANÁ, 1948a, p.44). 
Insere-se como prática discursiva governamental o enunciado "ação sistemática", que instaurou a separação interna do Estado do Paraná em três áreas distintas de atuação da política energética e constituiu as estimativas de um crescente consumo de energia. Dessa forma, o governo constrói discursivamente a responsabilidade de estabelecer um planejamento de curto, médio e longo prazo cuja saída imediata seria a retomada de alguns projetos de hidrelétricas, entre eles o da Usina Hidrelétrica Capivari/Cachoeira, e o início de uma ofensiva estadual na elaboração e construção de novos projetos, entre eles o de Salto Grande do Iguaçu. Sobre estes dois empreendimentos, convêm ressaltar que os primeiros estudos de Capivari/ Cachoeira datam de 1913 e que a ideia de uma central no Salto Grande do Iguaçu vem já da década de 1920.

Segundo Lupion, na mesma época em que a prefeitura de Curitiba adquiriu a propriedade das quedas do Capivari, comprou também as terras e os direitos necessários para o aproveitamento deste salto do Rio Iguaçu, conforme consta em Escritura Pública de 09 de dezembro de 1926, nas folhas 391 - Livro 1 do Cartório do $3^{\circ}$. Ofício de Notas de Homero F. do Amaral. Naquela época, tanto Capivari/Cachoeira quanto Salto Grande do Iguaçu foram idealizadas como solução aos problemas da falta de energia na capital. No entanto, na época de Lupion, a formação de um sistema de eletrificação tem como objetivo dar visualidade a um governo "preocupado" com uma interligação regional e que deixa de buscar interesses exclusivos "de uma determinada localidade, para abranger todas as localidades de uma determinada zona, devidamente conjugadas". Assim, o governo passa a ser um "poderoso centro produtor de energia hidroelétrica" (PARANÁ, 1948a, p.46-47).

Com o intuito de gerenciar as questões ligadas a este plano hidroelétrico e para atender às políticas nacionais de departamentalização dos setores energéticos nos Estados brasileiros, o governo de Lupion criou, com a Lei $\mathrm{n}^{\circ} 113$ de 15 de outubro de 1948, o Departamento de Águas e Energia Elétrica (DAEE). Conforme o Artigo $2^{\circ}$, alíneas "a" e "c" da referida Lei, as principais competências do DAEE eram: "estudar os problemas de suprimento de Energia Elétrica, elaborando planos de aproveitamento racional dos recursos hidráulicos e das instalações existentes" e "estudar as reservas de energia hidráulica do Estado, levantando o cadastro das quedas de água e executando serviços de hidrometria" (PARANÁ, 1948b, p.1). Esta última tarefa deveria ser feita com a colaboração da Divisão de Águas do Ministério da Agricultura.

Nesse sentido, uma das primeiras iniciativas do DAEE foi a elaboração do "Plano Hidroelétrico Paranaense Moysés Lupion"23 entregue à Secretaria de Viação e Obras Públicas no dia 30 de março de 1949 pelo seu Diretor Engenheiro Luis Orlando. Tal plano foi dividido em duas partes, sendo que na primeira se fez um breve histórico da formulação do documento e apresentou o Estado do Paraná como o possuidor do maior recurso hidráulico do país. Já consta, nesta primeira parte, um levantamento estatístico de aproximadamente 350 saltos distribuídos nos rios que compunham as bacias do Iguaçu, Ivaí, Litoral, Paraná, Paranapanema, Ribeira e Tibagi. Além disso, o documento contém tabelas com estimativas do potencial

${ }^{23}$ Daqui adiante denominado apenas por "Plano Hidro-Elétrico Paranaense". 
hidráulico dos rios paranaenses observados até dezembro de 1948. Para estes estudos da potência energética dos rios paranaenses, o DAEE contou com o apoio da Divisão de Águas do Ministério da Agricultura que instalara uma Seção Departamental em Curitiba para avançar os estudos pluvio-fluviométricos dos rios que também interessavam à União, principalmente o Paraná e o Iguaçu, os dois que apresentavam os maiores indicadores preliminares de potência (PARANÁ, 1949, p.9-13).

Para a elaboração do Plano Hidro-Elétrico Paranaense, o DAEE se valeu de uma série de estudos e apontamentos que o agente de política energética nacional fazia no Estado do Paraná em obediência ao Plano Nacional de Eletrificação. Este plano nacional foi apresentado em janeiro de 1947 pelo Conselho Federal de Comércio Exterior e seu principal objetivo era o de atender as necessidades do desenvolvimento econômico do Brasil através de uma "racionalização progressiva de sua indústria de energia elétrica" (PARANÁ, 1949, p.7). Dessa forma, o que foi denominado por "Plano Hidro-Elétrico Paranaense Moysés Lupion" tinha mais semelhanças com o governo federal do que com o governador que o denomina. Segundo Siqueira et al (1994), para elaborar o referido documento, o DAEE se inspirou no Plano Nacional de Eletrificação concluído ainda em 1946 e que previa, justamente, a ampliação dos recursos geradores do país (SIQUEIRA et al, 1994, p.96). Além disso, o Plano Nacional de Eletrificação propunha justamente as diretrizes apresentadas e defendidas por Lupion no Paraná que eram:

[...] a ação supletiva do Estado à da iniciativa privada; a interligação de sistemas isolados de energia; a constituição de empresas estatais ou de economia mista para viabilizar as obras necessárias; e a instituição de um "órgão nacional de eletricidade", que centralizaria as atribuições de planejamento de fiscalização de outros “órgãos regionais auxiliares" (SIQUEIRA et al., 1994, p.96).

Sendo assim, as ações do governo paranaense no tocante à construção de hidrelétricas ecoam as iniciativas federais no bojo de uma política energética voltada à centralização da produção e à construção de inúmeras hidrelétricas. Em linhas gerais, o plano paranaense obedeceu rigidamente aos projetos nacionais, aceitando a política de estruturação e a tendência centralizadora e reguladora de interligação e coordenação das operações de geração e transmissão de energia elétrica. Daí as afirmações de Lupion à Assembleia Legislativa em 1948 sobre o projeto de divisão do Estado em zonas de operação e não mais em localidades, definindo com isto, um "grande sistema regional de energia elétrica" para o Paraná (PARANÁ, 1949, p.13). Ainda de acordo com Siqueira et al (1994), o plano desenvolvido pelo governo paranaense, previa um conjunto de obras em duas etapas, sendo que na primeira seriam construídas a Central de Cotia (22.371 kW), a Usina de São João (5.816,46 kW), Santa Fé e Caiacanga (2.237,1kW cada). Já na segunda etapa, seriam construídas usinas maiores como a de São Sebastião (119.312 kW) e Salto Grande do Iguaçu (14.914 kW) (SIQUEIRA et al., 1994, p. 98). A Figura 1 mostra a 
Figura 1 - Plano Hidro-Elétrico Paranaense Moysés Lupion

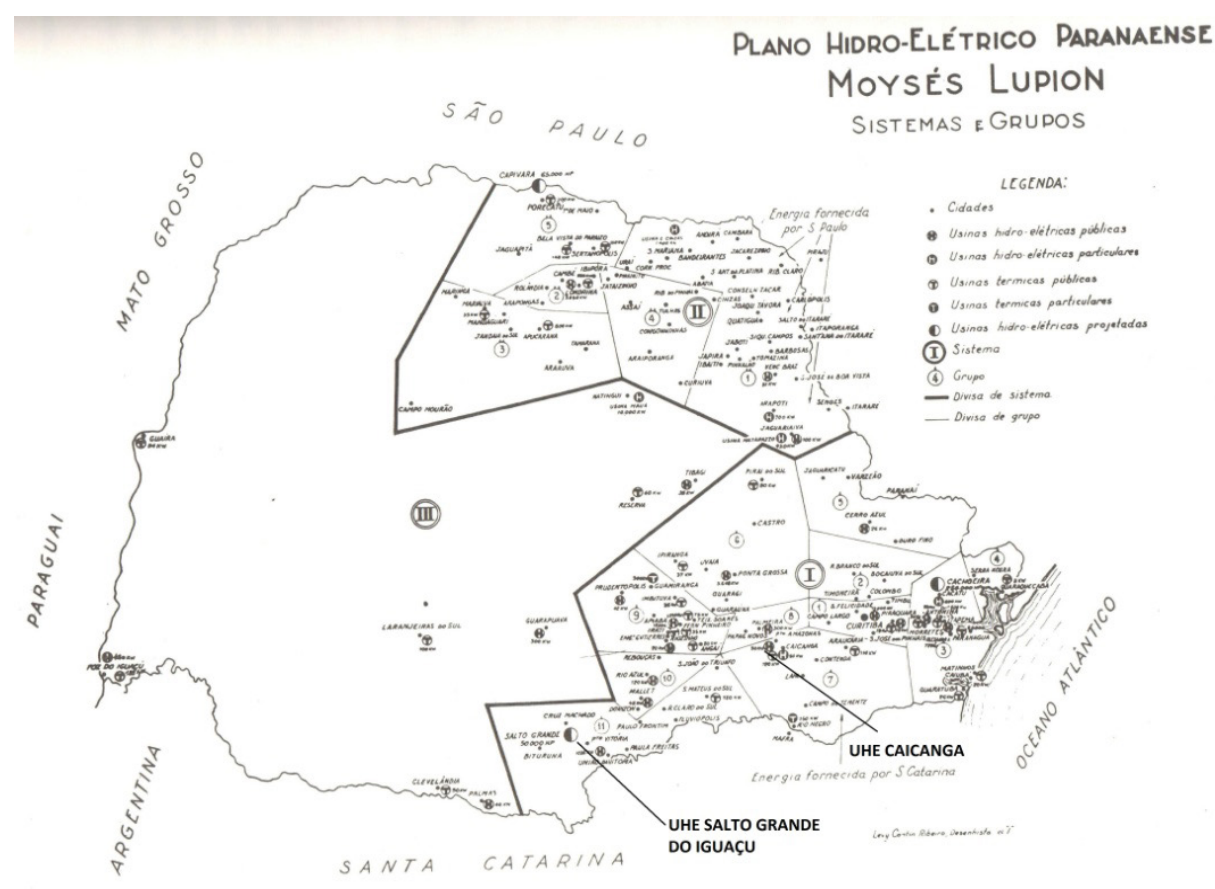

Fonte: Paraná (1949, p.16) com adaptações do autor.

divisão geográfica e sistemática das ações propostas pelo Plano Hidro-Elétrico Paranaense de 1948.

Como se percebe, a Figura 01 mostra que o plano obedeceu a divisão proposta em 1948 onde o Estado do Paraná contaria com três grandes áreas: (I) Curitiba, arredores e sul; (II) Norte e (III) Centro, Oeste e Noroeste. As prioridades para eletrificação se detinham nas regiões I e II, principalmente pelo aumento da demanda e precariedade dos serviços prestados pelas concessionárias. Esta visão sistêmica insere os recursos hídricos de cada região dentro de um planejamento estratégico que priorizava a hidroeletricidade. O Rio Iguaçu, em destaque na Figura 01, comporta já em 1949 duas hidrelétricas, a de Caiacanga e a de Salto Grande do Iguaçu, que contribuiriam para solucionar a falta de energia do Sistema I, prioridade do governo de Lupion. Para os propósitos deste artigo, destaco o empreendimento de Caiacanga que, pelas projeções do Plano, deveria ser construído ainda no início da década de 1950. Sendo assim, é possível aprofundar a partir do Plano Hidro-elétrico Paranaense de 1949 um pouco mais sobre a história desta primeira "hidrelétrica" do rio Iguaçu construída em 1955, como apontam os documentos que passo a analisar. 


\section{A Hidrelétrica Caiacanga: estudos, construção e avaliações}

Embora a hidrelétrica do Caiacanga represente um marco histórico na construção de barragens e hidrelétricas no rio Iguaçu, pouco se sabe sobre sua história. Durante nossa pesquisa encontramos poucos documentos nos arquivos visitados ${ }^{34}$ e alguns deles não estão disponíveis em arquivos públicos. Contudo, mesmo com a carência de fontes, é possível afirmar que o Rio Iguaçu entrou definitivamente nos planos hidroenergéticos tanto estadual quanto nacional a partir da década de 1950, primeiramente com o desenvolvimento do "Plano Hidroelétrico Paranaense" e, depois, por meio de uma política de eletrificação do Estado sob a responsabilidade da Companhia Paranaense de Energia (COPEL). Nesse sentido, os estudos apontados no plano de Lupion e alguns relatórios e pareceres técnicos elaborados a partir de 1951 fornecem dados suficientes para percebermos uma releitura do espaço hídrico do Iguaçu, com a contagem dos saltos e a medição de altura e potencial hidroenergético colocando-o entre os rios mais importantes para o "desenvolvimento de energia elétrica".

No entanto, os primeiros estudos no salto Caiacanga datam de 1907 e, caso a construção se efetivasse dentro do que fora contratado na época, esta seria a primeira hidrelétrica construída no Estado do Paraná. Entre os estudos e as ações políticas, econômicas e burocráticas que envolveram a Usina de Caiacanga desde o início do Século XX e a efetiva construção desta central hidrelétrica no início da década de 1950, existe um vazio documental. Desde que cessaram as discussões sobre o primeiro contrato que envolvia a sua construção nos relatórios oficiais do governo do Paraná em 1914, a Usina de Caiacanga só foi lembrada com o pesar de sua não instalação e do que representaria para o Estado caso estivesse em operação. O projeto de Caiacanga só voltou a ser cogitado em 1949 com o Plano Hidro-Elétrico Paranaense. Este, por sua vez, desconsiderou as discussões que historicamente envolveram a construção desta central hidrelétrica e apresenta uma breve nota sobre os estudos para a sua construção. Porém, através deste documento percebemos que as águas do Caiacanga já eram aproveitadas para fins hidroelétricos por uma empresa particular, a Fazenda São Luiz que, de alguma forma, conseguiu a permissão para ali instalar uma usina que gerava $40 \mathrm{~kW}$ de energia. Sendo assim, podemos afirmar que existiu uma negociação entre o Estado do Paraná e o proprietário da referida fazenda no sentido de utilizar um espaço que, historicamente esteve amarrado às concessionárias de energia elétrica que serviram à Capital: Hauer Junior e Cia, The South Brazilian Railways e Companhia Força e Luz do Paraná.

Dentro do "Plano Hidro-Elétrico Paranaense", os estudos sobre a usina de Caiacanga faziam parte de um conjunto de pequenas centrais que, divididas em grupos, abasteceriam as pequenas localidades que lhe faziam limites ou estavam próximas. Este conjunto de centrais de pequeno porte recebeu a designação de "Usinas dos Grupos", sendo Caiacanga pertencente ao Grupo $\mathbf{n}^{\circ}$

\footnotetext{
${ }^{34}$ Biblioteca Pública do Paraná, Arquivo Público do Paraná, Instituto Histórico e Geográfico do Paraná, Biblioteca do Centro de Hidráulica e Hidrologia Prof. Parigot de Souza (CEHPAR), Biblioteca e Arquivo da Companhia Paranaense de Energia (COPEL), Acervo Histórico da Tractebel S/A e Centro de Documentação (CEDOC) da Agência Nacional de Energia Elétrica (ANEEL).
} 
7 que comportaria, além dela, três termoelétricas em funcionamento (PARANÁ, 1949, p.43). A região de abrangência englobava os municípios de Porto Amazonas, Araucária e Lapa onde se distribuiria a potência de $2.000 \mathrm{HP}(1.500 \mathrm{~kW})$ de energia gerada por Caiacanga.

Pelo Plano Hidro-Elétrico Paranaense, a usina deveria ser construída na margem direta do Rio Iguaçu, no intuito de aproveitar as instalações já existentes da Fazenda São Luis. O Salto aproveitável seria de 12 metros necessitando apenas da construção de uma pequena barragem de 3 metros de altura, de onde sairia o canal a ser escavado na rocha e que mediria 350 metros de comprimento (PARANÁ, 1949, p.43) A Figura 2 mostra o levantamento topográfico do Rio Iguaçu no espaço de abrangência do Salto Caiacanga e define o local exato da construção da barragem, dos 350 metros do canal e a usina na margem direita. Esta imagem é bastante sugestiva, uma vez que, desde o início do século já se faziam estudos e projeções topográficas, pluviométricas e hidrológicas desta parte do Rio Iguaçu, conforme mostrou Karpinski (2011). Tal imagem inaugura um novo agente discursivo na constituição das paisagens e lugares dos rios: o discurso imagético das escalas.

Figura 2- Levantamento topográfico do Salto Caiacanga

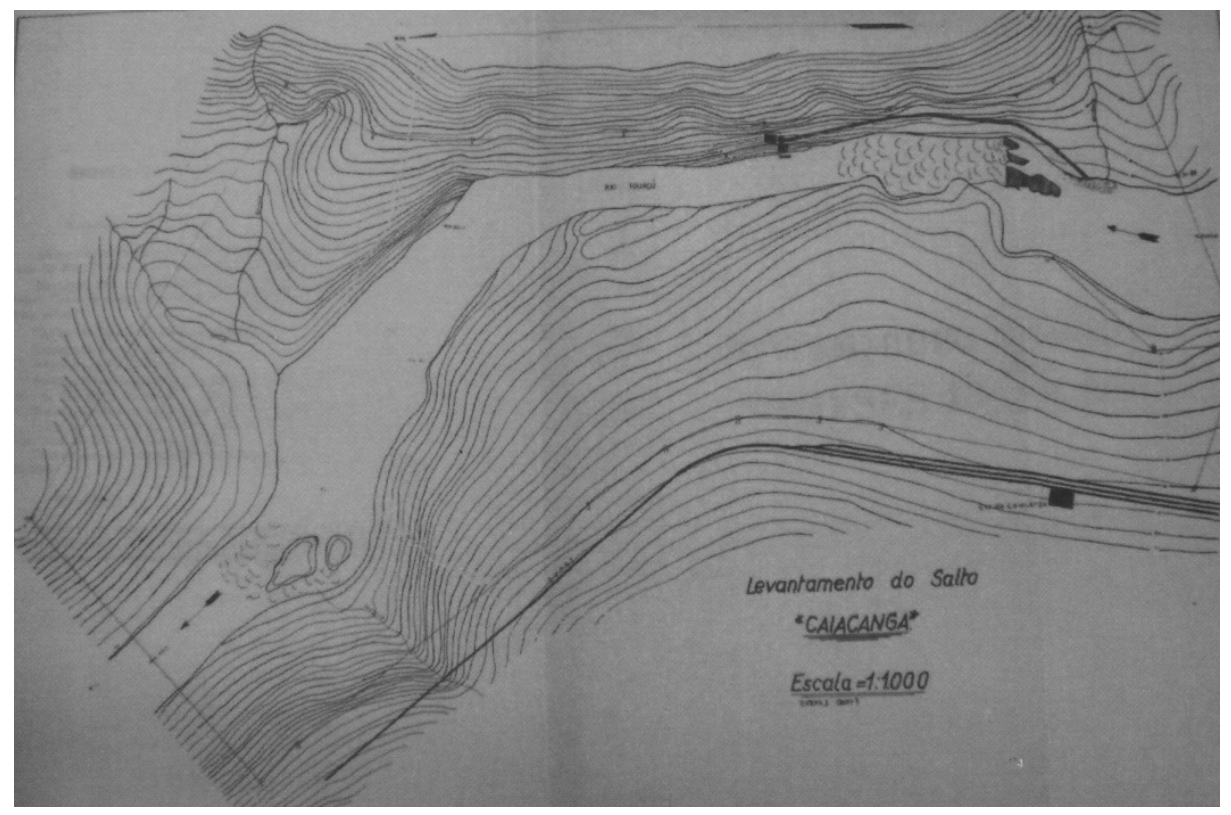

Fonte: Paraná (1949, p.44)

Pela imagem, visualiza-se o Salto Caiacanga sem a necessidade da constituição de descrições narrativas e isto, no meu entendimento, operou uma significativa transformação nas formas de representação e apropriação dos espaços hídricos. Nesse sentido, o rio passou a ser 
calculado, medido e mapeado de forma impessoal e, até mesmo, sem autoria, pois no relatório não importa mais o autor e nem mesmo o rio, mas sim a projeção, a possibilidade, a usina.

Pelo levantamento apresentado na Figura 2 temos a forma topográfica e a que se definirá, a partir dos anos 1950, como a mais "apropriada" para os estudos sobre o rio, não apenas neste salto específico, mas em todos os outros que foram apresentados como espaços de possíveis hidrelétricas. A partir dos anos 1950 o que se procurou no rio Iguaçu foi seu "potencial hidráulido" e, com as implicações deste novo enunciado, o Iguaçu passou a ser inserido nos planos e projetos de eletrificação como o rio de maior potencial hidráulico do Paraná. Contudo, para que esse aproveitamento do Iguaçu se concretizasse seria necessário ainda vários anos de estudos e grandes investimentos, principalmente para os outros saltos do rio, já que o Caiacanga, apesar das especulações de quase quarenta anos, não atendeu às expectativas do governo, como aponta o relatório técnico de 1951.

Este relatório, assinado por Alberto Pereira Pinto, diretor da empresa contratada pelo DAEE no governo de Lupion é, na verdade, um aglomerado de opiniões sobre o desenvolvimento do Plano Hidroelétrico Paranaense. Pelo que se percebe, os estudos foram feitos por engenheiros brasileiros e estadunidenses num consórcio firmado entre as Linhas Nelson Limitada de Curitiba e a Burns and Roe, Inc. de New York. Entregue em setembro de 1951, este relatório analisou a situação da construção de várias hidrelétricas previstas no plano hidroelétrico de Lupion, entre elas Caiacanga, com a descrição das obras feitas naquele ano. O principal objetivo deste estudo foi o de fornecer dados concretos sobre os recursos econômicos necessários para a execussão dos projetos hidrelétricos. Com estes dados em mãos e com a legitimidade que gozavam os órgãos internacionais de pesquisa, o governo almejava recorrer a financiamentos externos.

Sendo assim, este estudo além de tornar visível as relações econômico-financeiras desencadeadas pelo "plano hidro-elétrico parananese" representa também uma "memória técnica" da construção do empreendimento de Caiacanga. Embora este termo seja usado de forma distinta em outras áreas do conhecimento, o emprego nesta discussão por entender que "memória técnica" também pode abarcar um conjunto de documentos que tornam possíveis as análises históricas do processo de constituição e construção de empreendimentos advindos de tecnologias que variaram ao longo do tempo. Nesse sentido, podemos englobar como "memória técnica" não apenas os materiais técnicos ou a "evolução" das tecnologias que tornaram possíveis determinadas obras, mas também aquilo que possibilitou a explicação destas mudanças: os relatórios, os estudos, os desenhos, os mapas, as plantas, a metodologia empregada, enfim, tudo aquilo que tenha dado condição de possibilidade ao empreendimento.

No caso específico das hidrelétricas, toda a documentação escrita ou audiovisual poderia ser considerada como "partes de uma memória técnica" que, embora com linguagens e tipologias próprias, possibilita a escrita histórica de um longo processo pelo qual se constituíram os discursos e as técnicas que legitimaram suas construções. A partir dos relatórios técnicos, a tecnologia se constitui no discurso e a ele se agrega como parte legitimadora das práticas 
de construção de barragens, desvios, reservatórios e usinas que modificaram por completo determinadas paisagens hídricas. ${ }^{45}$

Este primeiro relatório sobre a Hidrelétrica Caiacanga traz melhores detalhes do projeto, com análises técnicas da altura da barragem, local da usina, produção e custo previsto para cada kW/h. De antemão pode-se perceber que o projeto era limitado, pois na primeira parte do estudo já aparecem os principais problemas da usina: $1^{\circ}$ ) projeto pequeno, limitado e incapaz de abastecer a região sozinho; $2^{\circ}$ ) o valor de $\$ 0.04$ (ou Cr $\$ 0,802$ ) por $\mathrm{kW} / \mathrm{h}$, fora os custos da rede de transmissão, foi considerado elevado demais para encorajar o uso generalizado de energia e, consequentemente, atrair financiamentos externos; $3^{\circ}$ ) a construção da usina deveria ser do lado esquerdo e não no direito como foi proposto no estudo prévio, pois tornaria desnecessária a construção do canal no lado direito até a usina (PARANÁ, 1951, p.59).

Esta terceira conclusão advinha, principalmente, das implicações causadas pela existência de uma estrada de ferro nas proximidades do salto. Pelo que se percebe no relatório de 1951, a ferrovia impedia a elevação da barragem, pois, se fosse assim, o reservatório alcançaria os trilhos e impediria o tráfego. Desta forma, com um reservatório menor, haveria um prejuízo na quantidade de energia a ser gerada e isto pode ser uma boa explicação para a não efetivação da construção da Usina Caiacanga no início do Século XX. Como a ferrovia foi construída no vale acima do salto, sua cota limitou a altura da barragem "assim como a quantidade de energia e armazenamento de água que poderiam ser obtidos neste local se fosse viável uma barragem mais alta" (PARANÁ, 1951a, p.61).

Devido a esta especificidade, os engenheiros estadunidenses afirmaram que a usina deveria ficar na margem esquerda do rio, adjacente ao traçado da ferrovia e não na direita, como apontava o plano original. Com esta mudança, "o custo da construção seria muito mais baixo devido à facilidade de transporte de material pela ferrovia e devido às melhores condições topográficas da margem esquerda para a construção de um canal ou tubulação adutora" (PARANÁ, 1951a, p.61). Segundo o laudo, a "Rede Viação Paraná - Santa Catarina" não faria objeções à "construção na sua propriedade da margem esquerda" o que resolveria de uma vez por todas os problemas entre a Usina e a Ferrovia (PARANÁ, 1951a, p.61). Contudo, antes de se concluírem os estudos e a definição de qual lado a adução da água deveria ser feita, o empreiteiro principiou a construção do canal sem revestimento escavado na rocha da margem direita.

Além disso, as escavações para a casa de máquinas também se iniciaram em 1951, o que tornou as especulações das construções do lado esquerdo inúteis e o trabalho do estudo desnecessário, pois a empreiteira obedeceu ao projeto original sem levar em conta a opinião dos técnicos contratados posteriormente pelo governo para viabilizar as mudanças capazes de tornar o projeto viável e economicamente competitivo. Com estas obras já feitas em 1951, os engenheiros apenas refizeram os cálculos e concluíram que a usina contaria com "dois grupos

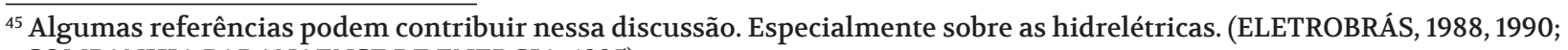
COMPANHIA PARANAENSE DE ENERGIA, 1995). 
de $1125 \mathrm{KW}$ operando com queda de $15 \mathrm{~m}$ (49,2 pés) e um grupo de $243 \mathrm{KW}$ operando com queda de $8 \mathrm{~m}$ (25,94 pés)" com uma "produção anual de 8.567.280 KWhr" (PARANÁ, 1951a, p.60).

Sobre este relatório, é importante ressaltar ainda que, embora tenha sido encomendado no governo de Lupion, foi no mandato de Bento Munhoz da Rocha que ele foi entregue, como atividades programadas do Plano Hidro-Elétrico Paranaense "Moysés Lupion". Segundo Siqueira et al (1994), o governador Bento Munhoz da Rocha fez grande oposição ao governo de Lupion, criticando a postura deste governo nas obras de eletrificação do Paraná. Contudo, apesar desta oposição e crítica, não se notou modificação no padrão de atuação estatal no setor de geração de energia. "O DAEE continuou a encampar usinas municipais, a instalar geradores de emergência em localidades em situação crítica e a construir usinas pequenas nas localidades de Cotia, São João, Laranjinha, Caiacanga" (Siqueira et al, 1994, p.103).

As críticas de Munhoz da Rocha ao governo de Lupion se deram, sobretudo, às contradições contratuais do setor de energia elétrica e a falta de um plano racional de obras. Segundo Munhoz da Rocha, o plano hidroelétrico de Lupion representava um programa "que envolvia muito de aspiração, mas quase nada de exame, de análise, de dados estatísticos, de padronização, de pesagem e de rumos consistentes para assegurar o êxito dos empreendimentos" (PARANÁ, 1951b, p.90).

Desta forma, a política energética paranaense inicia a década de 1950 demonstrando que, embora houvesse um plano hidroelétrico para prover o Estado de energia, seus projetos apresentavam-se frágeis diante da realidade econômica do Paraná. Além disso, a acusação que pesou às ações do DAAE na gestão de Lupion, os desvios de suas funções originais e as políticas voltadas ao financiamento das obras de geração de energia vão constituir um ambiente propício para profundas mudanças no cenário energético paranaense que culminará com a gradual assimilação do DAAE pela Companhia Paranaense de Energia (COPEL) criada em 1954 e que, aos poucos, assumiu as obras e projetos hidrelétricos construídos, em andamento e os projetados no Paraná. Com estas constantes mudanças departamentais, ocorreu também uma descentralização das responsabilidades de guarda e arquivo do acervo referente às primeiras Hidrelétricas. Depois do relatório encaminhado pela empresa "Linhas Nelson Ltda" em 1951, não encontramos mais documentação referente à continuidade das obras de Caiacanga. Somente a assertiva de que a usina foi concluída em 1955, último ano de mandato de Munhoz da Rocha. Quem noticiou o término da obra foi o mesmo governador que deu nome ao Plano HidroElétrico, Moysés Lupion, que em 1956 assumiu o governo pela segunda vez. Na mensagem que Lupion enviou à Assembléia em 1956 está a afirmação de que entre as obras do DAEE no ano de 1955 estava a conclusão da "usina Piloto de Caiacanga com a potência de 350 HP" (PARANÁ, 1956, p.105).

Pelo que se percebe, a escassez de documentação sobre Caiacanga se explica por dois motivos. O primeiro por ter sido construída sob a fiscalização do DAEE antes da fundação e consolidação da Copel. Desta forma, sem pertencer ao quadro de aquisições desta empresa, não se sabe ao certo onde estariam os documentos referentes à sua construção. Já o segundo 
motivo se deve a sua desativação precoce na década de 1970. Ainda hoje, partes do que foi esta usina são visíveis no salto Caiacanga, especialmente as ruínas da barragem, do canal adutor escavado na rocha em 1951 e do local onde possivelmente ficava a Casa de Máquinas. Por enquanto, não se sabe ao certo o que aconteceu após sua desativação, nem o "como" ou os "porquês" de ser desativada. Contudo, "restos" e "vestígios" de uma "usina em pedaços" compõe hoje a paisagem do salto Caiacanga e, no meu entendimento, impõe-se como um memorial do início das profundas transformações ambientais que o Rio Iguaçu sofreria a partir da década de 1960, principalmente com o avanço das tecnologias na construção de barragens para usinas hidrelétricas. Certamente, os poucos kWs fornecidos por Caiacanga até a década de 1970 não fariam falta ao imenso complexo hidrelétrico que seria viabilizado com pesados investimentos estatais e internacionais a fim de tornar o Rio Iguaçu um dos mais importantes no desenvolvimento de energia elétrica no país.

\section{Considerações finais}

Neste artigo, minha proposta foi a de iniciar um diálogo sobre história e hidrelétricas a partir de um recorte temporal distinto do que comumente tem se apresentado na historiografia e bibliografias especializadas nesta temática. De certa forma, problematizar a questão das hidrelétricas em temporalidades diversas podem fornecer subsídios para a compreensão dos processos históricos atuais e abrir outras possibilidades de análises para a atuação dos historiadores no debate interdisciplinar que nos impõe esta temática. Particularmente sobre o Rio Iguaçu, encontramos excelentes trabalhos, cujas análises partilham do sentimento de impotência dos atingidos diante dos projetos hidrelétricos e, principalmente, tornam visíveis as ações de resistência dos movimentos sociais.

Estes pesquisadores, dos quais me incluo, certamente, têm focalizado seus estudos a partir da década de 1970, período a partir do qual, se intensificou a construção das cinco grandes hidrelétricas existentes no Iguaçu (Foz do Areia, Segredo, Salto Santiago, Salto Osório e Salto Caxias). Nesse sentido, minhas indagações sobre a política energética paranaense das décadas de 1940 e 1950, bem como as discussões iniciais sobre o processo e a construção da hidrelétrica Caiacanga, vem como proposta de avançar as discussões sobre os processos que antecederam e legitimaram as construções de hidrelétricas neste rio. Historiar este processo pode contribuir para a emergência de novas perguntas e nos levar a um universo de fontes pouco exploradas em nosso ofício, especialmente os relatórios técnicos e estudos de viabilidade que, desde sua concepção, desconsideram a presença humana e não humana do meio ambiente ribeirinho aos saltos ou aos futuros reservatórios.

Foi por intermédio do relatório analisado neste artigo que conseguimos, por exemplo, encontrar vestígios de um processo histórico secular que envolveu a construção da primeira hidrelétrica no rio Iguaçu. Além disso, o relatório produzido pela parceria "Linhas Nelson Limitada" e "Burns and Roe" mostra as fragilidades da política energética e das formas 
tecnológicas ainda primárias no que diz respeito à projeção e construção de hidrelétricas na década de 1950. A documentação escassa e muitas vezes protegida por arquivos privados inacessíveis aos pesquisadores acadêmicos pode deslindar processos de uma história que necessita ser visualizada a partir de uma análise mais crítica.

\section{Referências}

CENTRO DE MEMÓRIA DA ELETRICIDADE DO BRASIL. Panorama do setor de energia elétrica no Brasil. Rio de Janeiro: Centro da Memória da Eletricidade no Brasil, 1988.

COMPANHIA PARANAENSE DE ENERGIA. Usina Hidrelétrica Foz do Areia: Rio Iguaçu: Memória técnica. Curitiba: COPEL, 1995.

DERROSSO, G. S.; ICHIKAWA, E. Y. A construção de uma usina hidrelétrica e a reconfiguração das identidades dos ribeirinhos: um estudo em Salto Caxias, Paraná. Ambiente \& Sociedade, São Paulo, v.17, n. 3, p. 97-114, 2014.

ELETROBRÁS. Memória técnica de sistemas de transmissão: roteiro básico. Rio de Janeiro: Eletrobrás, 1990.

ELETROBRÁS. Memória técnica de usinas hidrelétricas: roteiro básico. Rio de Janeiro: Eletrobrás, 1988.

FLEURY, L. C.; ALMEIDA, J. A construção da usina hidrelétrica de Belo Monte: conflito ambiental e o dilema do desenvolvimento. Ambiente \& Sociedade, São Paulo, v. 16, n. 4, p. 141-158, 2013.

KARPINSKI, C. Navegação, cataratas e hidrelétricas: discursos e representações sobre o Rio Iguaçu (Paraná, 1853-1969). 2011. 375 f. Tese (Doutorado em História) - Universidade Federal de Santa Catarina, Florianópolis, 2011.

LAVERDI, R. A cidade que estava lá: tensões urbanas em Porto Velho a partir da construção das Hidrelétricas de Santo Antônio e Jirau. Historia \& Perspectivas (UFU), Uberlandia,v. 44, p. 267315, 2011.

MAIA, L. C. et al. (Org.). Hidrelétricas e atuação do Ministério Público na América Latina. Porto Alegre: Letra\&Vida: Red Latinoamericana de Ministério Público Ambiental, 2013.

NAVAL, L.P.; PARENTE, T.G. (Org.). Impactos socioambientais: o desafio da construção de hidrelétricas. Goiânia: Cânone Editorial, 2009.

PARANÁ. Governo do Estado. Mensagem apresentada à Assembléia Legislativa do Estado por ocasião da abertura da Sessão Ordinária de 1956 pelo Senhor Moysés Lupion, governador do Estado. Curitiba: [s.n.], 1956. 
PARANÁ. Governo do Estado. Estudos e opinião sobre os desenvolvimentos hidro-eletricos propostos e em construção pelo Estado do Paraná: primeira fase de um programa de energia do Estado que inclui os projetos de Cotia, Capivari-Cachoeira, Caiacanga, Carvalhopolis, Campo Mourão e Santa Fé. Curitiba: Linhas Nelson Limitada; New York: Burns and Roe, Inc., 1951a.

PARANÁ. Governo do Estado. Mensagem apresentada à Assembléia Legislativa do Estado por ocasião da abertura da sessão legislativa de 1948 pelo Senhor Moysés Lupion, Governador do Estado. Curitiba, 1948a.

PARANÁ. Governo do Estado. Mensagem apresentada à Assembléia Legislativa do Estado por ocasião da abertura da $1^{\text {a }}$ Sessão Ordinária da $2^{a}$ Legislatura pelo Senhor Bento Munhoz da Rocha Neto, Governador do Paraná. Curitiba: [Imprensa Oficial], $1951 b$.

PARANÁ. Lei $\mathrm{n}^{\circ} 113$ de 15 de outubro de 1948. Cria o Departamento de Águas e Energia Elétrica e dá outras providências. Diário Oficial do Estado do Paraná, Curitiba, 19 de outubro de 1948, ano 36, n.194, p.1, 1948 b.

PARANÁ. Secretaria de Viação e Obras Públicas. Departamento de Águas e Energia Elétrica. Plano Hidro-Elétrico Paranaense Moysés Lupion: $1^{\mathrm{a}}$ e $2^{\mathrm{a}}$ parte. Curitiba, 1949.

PINTO, L. F. De Tucuruí a Belo Monte: a história avança mesmo? Boletim do Museu Paraense Emílio Goeldi. Ciências Humanas, Belém, v. 7, n. 3, p. 777-782, set.- dez. 2012.

ROCHA, H. J. O controle do espaço-tempo nos processos de instalação de hidrelétricas. Tempo Social, São Paulo, v.26, n.1, p.259-280, 2014.

SANTOS, S. C.; REIS, M. J. Memória do setor elétrico na Região Sul. Florianópolis: UFSC, 2002.

SIEBEN, A.; CLEPS JR., J. Política energética na Amazônia: a UHE Estreito e os camponeses tradicionais de Palmatuba/Babaçulândia (TO). Sociedade E Natureza, Uberlândia, ano 24, n.2, p.183-196, 2012.

SILVA, R. G. S.; SILVA, V. P. Os atingidos por barragens: reflexões e discussões teóricas e os atingidos do assentamento olhos d'água em Uberlândia-Mg. Sociedade E Natureza, Uberlândia, ano 23, n.3, p.397-408, 2011.

SIQUEIRA, M. D. et al. (Coord.). Um Século de eletricidade no Paraná. Curitiba: Companhia Paranaense de Energia, 1994.

VERDUM, R. (Org.). Integração, usinas hidrelétricas e impactos socioambientais. Brasília: INESC, 2007. 